\title{
RELAÇÕES ENTRE ADULTOS E CRIANÇAS: O QUE DIZEM AS NARRATIVAS DAS CRIANÇAS?
}

\author{
GABRIELA BARRETO DA SILVA SCRAMINGNON \\ https://orcid.org/0000-0002-3819-8302 \\ Universidade Federal do Estado do Rio de Janeiro
}

RESUMO Este texto, resultado de uma pesquisa de doutorado, discute as relações estabelecidas entre adultos e crianças na contemporaneidade, a partir da escuta de crianças de seis a dez anos, moradoras da Região Metropolitana da cidade do Rio de Janeiro. A pesquisa de campo aconteceu em um Instituto de Artes. 0 estudo teve como estratégias metodológicas a observação e a realização de entrevistas coletivas. Traz para o debate as contribuições da antropologia filosófica de Walter Benjamin, interlocutor teórico-metodológico do estudo. Aborda as contribuições dos Estudos da Infância como campo interdisciplinar de conhecimento, que fornece elementos para pensar a infância e a criança no âmbito das ciências humanas e sociais. Problematiza as condições que a contemporaneidade tem oferecido para as relações entre adultos e crianças. Enfatiza a necessidade de pensar a criança como semelhante ao adulto na sua humanidade, valorizando-a, em busca de estabelecer com ela uma relação de alteridade. Nas análises, as crianças, como narradoras privilegiadas de sua condição, dão pistas sobre o mundo que construímos para elas. Ser criança é apontado como condição que espera do adulto escuta, credibilidade, tempo, paciência, calma. As narrativas das crianças abrem possibilidades para a reflexão sobre esse mundo.

Palavras-chave: Criança. Infância. Relação entre crianças e adultos. Narrativas. contemporaneidade.

\section{ABSTRACT RELATIONSHIPS BETWEEN ADULTS AND CHILDREN: WHAT DO CHILDREN'S NARRATIVES SAY?}

This text, result of a doctoral research, discusses the relationships established between adults and children in contemporary times, from listening to children aged six to ten years, living in the Metropolitan Region of the city of Rio de Janeiro. The research field took place in an Arts Institute. The methodological strategies applied to the study were the observation and conduction of collective interviews. This in- 
vestigation, of which theoretical-methodological interlocutor is Walter Benjamin, brings to the debate the contributions of his philosophical anthropology. It approaches the contributions of Childhood Studies as an interdisciplinary field of knowledge, which provides elements for thinking childhood and children in the scope of Human and Social Sciences. It discusses the conditions that the contemporaneity has been offering to the relationships between adults and children. It emphasizes the necessity to face the child as someone similar to an adult concerning his/her humanity, valuing him/her, seeking to establish with him/her an otherness relation. In the analysis, the children, as privileged narrators of their condition, give clues of the world we build for them. Being a child is seen as a condition that expects listening, time, patience and calmness from the adult. The children's narratives open new possibilities for reflecting about this world.

Keywords: Child. Childhood. Relationship between children and adults. Narratives. Contemporaneity. DICEN LAS NARRATIVAS DE LOS NIÑOS?

Este texto, resultado de una investigación de doctorado, discute las relaciones establecidas entre adultos y niños en la contemporaneidad, a partir de la escucha de niños de seis a diez años, que viven en la Región Metropolitana la ciudad de Río de Janeiro. La investigación de campo tuvo lugar en un Instituto de Artes. El presente estudio tuvo como estrategias metodológicas la observación y la realización de entrevistas colectivas. Aporta al debate las contribuciones de la antropología filosófica de Walter Benjamin, interlocutor teórico-metodológico del estudio. Aborda las contribuciones de los Estudios de la Infancia como un campo interdisciplinario de conocimiento, que proporciona elementos para pensar la infancia y el niño en el contexto de las Ciencias Humanas y Sociales. Problematiza las condiciones que la contemporaneidad ha ofrecido para las relaciones entre adultos y niños. Enfatiza la necesidad de pensar el niño como semejante al adulto en su humanidad, la valora para establecer una relación con ella de alteridad. En los análisis, los niños, como narradores privilegiados de su condición, dan pistas sobre el mundo que construimos para ellos. Ser niño es considerado como condición que espera del adulto escucha, credibilidad, tiempo, paciencia, calma. Las narrativas de los niños abren posibilidades de reflexión sobre este mundo.

Palabras clave: Niño. Infancia. Relación entre niños y adultos. Narrativas. Contemporaneidad. 


\section{Introdução}

Nas ciências humanas e socias, a pesquisa com criança vem apresentando avanços no que tange à condição da criança nas investigações. Esse movimento é responsável pela diferença entre a pesquisa feita sobre as crianças, a partir de informações fornecidas pelos adultos, e a pesquisa com as crianças, partindo de suas concepções, o que significa ouvi-las compreendendo que suas narrativas se constituem a partir das relações sociais que produzem.

Nesse sentido, o desafio posto é romper com o lugar que coloca as crianças como pretexto de investigação, assegurando caminhos para que - em seus próprios termos - a criança - "essa pessoa de pouca idade, que produz cultura, é nela produzida, brinca, aprende, sente, cria, cresce e se modifica, ao longo do processo histórico que constitui a vida humana", e que, igualmente, é "constituída a partir de sua classe social, etnia, gênero e por diferenças físicas, psicológicas e culturais" (KRAMER, 2011) - tenha garantido seu lugar no percurso investigativo.

0 reconhecimento das falas das crianças, enquanto capazes de falar por si e sobre si como dado de pesquisa, é apontado por Macedo e demais autores (2012) como uma questão a ser enfrentada na produção do conhecimento.

É ainda um desafio para nós, pesquisadores da infância, aprender a perceber as crianças como agentes de seu tempo, como pessoas inseridas em determinado contexto; aprender a nos interessarmos pelo que, de fato, elas têm a partilhar, no que elas têm a nos acrescentar. Sua participação ativa certamente desvelará aspectos específicos, diferenciados e, por isso mesmo, únicos. (MACEDO et al., 2012, p. 101)

Ao discutir a participação das crianças na pesquisa científica, Campos (2008) afirma que a presença das crianças na pesquisa não é nova. Para a autora, "o debate sobre a con- dição em que ela toma parte na investigação científica é que é uma tendência recente, sendo este o último grupo dominado a ingressar nesse movimento de revisão dos modelos de pesquisa" (CAMPOS, 2008, p. 35).

No âmbito dos Estudos da Infância, há um conjunto de indicadores que demonstram uma definição na constituição de um caminho próprio da produção do conhecimento, centrado na infância que, segundo Sarmento (2009), vem expandindo-se por todo o mundo. Sobre essa questão, Christensen \& James (2005, p. 8) ressaltam que tem sido preocupação constante de investigadores "o reinventar de metodologias e ferramentas de investigação que lhes permitam desocultar e incluir as vozes das crianças na investigação".

A antropologia enfatiza a dimensão da cultura, a necessidade de pesquisar a diversidade, de estranhar o familiar e de compreender o outro nos seus próprios termos. No campo da psicologia, a proposta é a compreensão da infância a partir de um distanciamento da razão desenvolvimentista. A Sociologia da Infância problematiza a concepção que toma a criança como passiva em processos de socialização conduzidos por adultos e/ou instituições que dela se encarregam. A criança é aqui vista em seu potencial de criação.

Os Estudos da Infância consideram variáveis como classe social, gênero, etnia, religião, origem geográfica. Na perpectiva da história, da cultura, dos estudos da linguagem, das políticas públicas, das brincadeiras, dos processos de socialização, da participação infantil, das análises institucionais, das interações entre crianças e entre elas e os adultos, esse campo traz para o debate as crianças, lançando como desafio romper com os estereótipos e preconceitos em relação a elas e suas culturas, muitas vezes ainda tão estranhas para nós, adultos. Nesse sentido, olhar a experiência da infância na contemporaneidade é ir além dos 
muros da escola. No âmbito desses estudos, está a importância de investigações que indagam sobre ser criança em diferentes instâncias de socialização. Realizar pesquisas em diferentes contextos sociais possibilita conhecer os espaços destinados às crianças em nossa sociedade e as relações neles estabelecidas.

Este texto, resultado de uma pesquisa de doutorado, discute as relações estabelecidas entre adultos e crianças na contemporaneidade, a partir da escuta de um grupo de 15 crianças, com idades entre seis e dez anos, moradoras da cidade do Rio de Janeiro. A pesquisa de campo aconteceu no Instituto de Artes, ${ }^{1}$ organização não governamental sem fins lucrativos, empenhada na formação e produção artística cultural. A escolha do instituto como espaço para a realização da pesquisa considerou os seguintes aspectos: formação de um único grupo de crianças participando juntas de oficinas semanais; grupo com meninos e meninas; crianças moradoras de diferentes regiões da cidade e estudantes de diferentes redes de ensino, em sua maioria da rede pública; acesso aos responsáveis para esclarecimento da pesquisa e encaminhamento das autorizações.

A pesquisa de campo foi realizada durante o período de 11 meses, e teve como estratégias metodológicas a observação e a realização de entrevistas coletivas. Durante o processo de investigação, nas observações e conversas com as crianças a respeito da pesquisa, foi possivel definir a estratégia metodológica. Assim, considerando as interlocuções construídas com as crianças durante o período de observação, e as questões surgidas no trabalho de campo, a decisão foi pela realização das entrevistas co-

1 Por uma questão ética, a fim de preservar o nome da instituição e das crianças participantes da pesquisa, foram utilizados nomes fictícios. Em atendimento aos procedimentos éticos da pesquisa com crianças, antes de se iniciar o trabalho na instituição, foram entregues termos de consentimento aos pais e responsáveis pelas crianças, os quais foram assinados, autorizando a realização da pesquisa. letivas no formato de um jornal. Em um dos encontros, ao explicar que gostaria de entrevistá-las, contaram sobre uma brincadeira na qual simulavam um jornal, entrevistavam umas às outras e os adultos que participavam com elas no momento. Demonstraram muita alegria ao contarem a experiência, e durante a conversa, definimos que o jornal poderia ser uma boa ideia para as entrevistas.

A relação com as crianças mostrou que não há uma única forma, um jeito singular de fazer que ofereça a possibilidade de "encaixar" toda e qualquer investigação. Além das diferenças entre temas e objetivos, coloca-se a relevância de se conhecer o grupo e o contexto. 0 convívio com elas permitiu a desconstrução de ideias iniciais, como a tentativa de encontrar um elemento disparador para iniciar o diálogo durante as entrevistas. As crianças falam, conversam, são potentes, e mostram que a presença de recursos como formas de mediação não se coloca como condição para o diálogo com elas. $O$ interesse pelo assunto, pelo tema da conversa faz com que queiram ou não falar. As crianças ensinam aos pesquisadores que podem se desprender da artificialidade porque são capazes de conversar, e que a relação é elemento disparador do diálogo que se constrói com elas.

As entrevistas seguiram um roteiro pré-estruturado e foram gravadas e transcritas. Entre as questões de destaque no diálogo com as crianças, este texto irá discutir: o que as crianças falam da relação delas com os adultos, jovens, idosos? Como revelam em seus discursos a compreensão que têm de si, dos outros? Que temas, conversas e perguntas as crianças trazem? Os dados produzidos foram analisados e organizados, tendo como principal categoria analítica as narrativas das crianças sobre as relações estabelecidas entre elas e os adultos.

0 encontro com as crianças - e o que pôde ser visto e ouvido de suas experiências - é tra- 
tado no texto da seguinte forma: inicialmente, discute a concepção de infância com base nas contribuições da obra de Benjamin (1994; 1995; 1984; 2002; 2015). A construção de um saber que se situa no limiar entre o que já se sabe, memorialisticamente, dessa experiência de infância e o que não se sabe das experiências dos outros que habitam essa categoria hoje é o que há de mais convidativo no pensamento de Benjamin acerca da infância. A partir das contribuições do autor, é possível compreender as narrativas das crianças com o lugar onde também se faz história. No segundo e terceiro momentos do texto, a análise é construída a partir do que dizem as crianças das suas relações estabelecidas com os adultos. Por fim, são tecidas algumas considerações em torno das análises empreendidas.

\section{A infância como denúncia de um tempo}

Pensar a criança e a infância hoje apoia-se na compreensão de que cada época irá proferir o discurso que revela sua concepção em relação a elas. Na perspectiva da infância situada no tempo, na história e na cultura, e não como parte de um processo histórico evolutivo, natural e fatalista, a concepção de infância, neste texto, está fundamentada na obra de Benjamin que, ao formular teses sobre o conceito de história e tecer uma crítica à ideologia do progresso, convida a pensar categorias temporais tendo o desvio da infância como origem de uma nova ordem.

Sua reflexão nos convida a olhar para as relações estabelecidas entre adultos e crianças pensando sobre o que temos feito. Que respostas as crianças têm suscitado em nós? Como temos respondido? Para Benjamin (1994), uma época não se deixa capturar por seus contemporâneos a partir dos grandes movimentos, mas são os fragmentos constitutivos do coti- diano, pequenos detalhes, os estilhaços das grandes transformações.

Rompendo com uma postura evolucionista que trata o tempo de forma linear, como se a vida fosse uma sequência de etapas evolutivas, Benjamin (1984) apresenta outro conceito de história, no qual passado, presente e futuro estão entrecruzados. Com base nessa perspectiva de temporalidade, a história não surge de um ponto de partida primordial, ela pode ser constantemente refeita e recontada. Os conceitos de "origem e ruína", que podem ser compreendidos de forma diferenciada, ajudam a entender essa perspectiva.

A origem, apesar de ser uma categoria totalmente histórica, não tem nada a ver com a gênese. 0 termo origem não designa o vir-a-ser daquilo que origina, e sim algo que emerge do vir-a-ser e da extinção. A origem se localiza no fluxo do vir-a-ser como um torvelinho, e arrasta em sua gravitação o material originado. 0 originário não se encontra nunca no mundo dos fatos, e sua rítmica só se revela a uma visão dupla, que a reconhece, por um lado, como restauração e produção, e por outro, e por isso mesmo, como incompleta e inacabada. [...] A origem, portanto, não se destaca dos fatos, mas se relaciona com sua pré e pós-história. (BENJAMIN, 1984, p. 6768 , grifo do autor)

Diferentemente de um encadeamento causal, de um processo linear, infância, idade adulta e velhice constituem-se como categorias sociais, históricas e culturais, que recompõem permanentemente a experiência vivida. Para Pereira \& Jobim e Souza, "a vida humana pode ser pensada à luz dos conceitos benjaminianos de origem e ruína, em que a criança não é o ponto zero da existência humana nem a velhice seu ponto final" (1998, p. 34). Nessa crítica, o tema da infância ocupa lugar relevante. Em sua teoria crítica da cultura, Benjamin traz a infância para pensar a concepção de história. Ter uma infância é o desafio do historiador. E por que a infância? 
O que significa essa concepção de infância na história humana?

A capacidade da criança de enxergar o que o adulto não vê e sua incapacidade de entender certas palavras, de manusear objetos dando-lhes usos e significações ainda não fixados pela cultura faz lembrar que tanto os objetos, quanto as palavras estão no mundo para serem constantemente ressignificados por nossas ações. A infância pode ser vista alegoricamente como elemento capaz de desencadear o mundo da razão instrumental, trazendo à tona a crítica do progresso e da temporalidade linear. O homem como ser histórico tem uma infância, possibilidade de compreensão de uma época da história. A crítica feita à modernidade é também uma crítica à construção do olhar da infância na modernidade.

Historicamente, podemos ver que, apesar da existência das crianças, a concepção de infância nem sempre existiu como a entendemos hoje. 0 tema da infância tem sido objeto de estudo de muitos pesquisadores. Diferentes discursos constituem novas formas de ver a infância e as crianças. A concepção de infância não é algo natural; os papéis desempenhados pelas crianças variam de acordo com a organização social. Cada sociedade, com seus costumes e sua cultura, constitui essa concepção, nos dando pistas sobre o seu pensar em relação às crianças.

Benjamin não se propôs a realizar uma pesquisa histórica sobre a infância. Mas o filósofo, já no início do século XX, percebeu as crianças à medida que vivia os acontecimentos de sua época. Olhou de dentro, estando dentro, o que "revela um profundo e sensivel pensamento sobre a criança como indivíduo social e nos conta como ela vê o mundo com seus próprios olhos" (KRAMER,1993, p. 63).

A criança, no olhar benjaminiano, não está fixada, estática, a esperar que a cultura a preencha, ela está imersa na cultura, é parte e produtora de cultura. "Não são as coisas que saltam das páginas em direção à criança que as vai imaginando - a própria criança penetra nas coisas durante o contemplar" (BENJAMIN, 2002, p. 69). Benjamin aponta o movimento da criança diante do produto da cultura: "A criança quer puxar alguma coisa e torna-se cavalo, quer brincar com areia e torna-se padeiro, quer esconder-se e torna-se bandido ou guarda" (Idem, p. 93). Aqui, como na citação anterior, ele indica autoria, decisão, presença, que em nada se assemelham a uma ideia de infância a ser moldada ou cultivada de acordo com o desejo adulto. Sua visão de criança, que cria com liberdade na relação com essa cultura, se apresenta ainda mais uma vez quando afirma: “Não há dúvida que brincar significa sempre libertação. Rodeadas por um mundo de gigantes, as crianças criam para si, brincando, o pequeno mundo próprio" (BENJAMIN, 2002, p. 85).

A infância, em Benjamin, sai da perspectiva dos manuais explicativos de desenvolvimento e alça o patamar da reflexão das próprias relações dos homens na contemporaneidade. Para o autor, "as crianças não constituem nenhuma comunidade isolada, mas antes fazem parte do povo e da classe a que pertencem" (BENJAMIN, 2002, p.94). Assim, "o mundo da percepção infantil está impregnado em toda parte pelos vestígios da geração mais velha" (IDEM, p.96), pois não é apenas a cultura local, imediata, contemporânea que compõe o universo cultural que impregna o mundo da criança e de todos nós, mas a nossa história, a história da humanidade, ainda que contada não apenas em grandes livros bem recortados, mas em pequenos retalhos remendados, em pequenos contos, hábitos, formas de organização, de produção, na cultura.

Em sua obra, Benjamin destaca a possibilidade de interlocução com as crianças, o que pôs em prática quando dialogou com elas. Embora possa surpreender o leitor, a com- 
preensão de Benjamin em relação ao lugar das crianças na cultura pode ser observada também nas narrativas radiofônicas produzidas por ele, dedicadas a elas no programa de rádio A hora das crianças, apresentado entre os anos de 1927 e 1933, transmitido em emissoras de rádio de Berlim e Frankfurt. ${ }^{2}$ Sobre as narrativas, Benjamin faz uma crítica aos adultos quando questiona que estes podem ouvir no rádio "todo o tipo de programa que interessa a eles com informações especializadas. [...] E porque não se pode fazer estes programas especializados para crianças também?" (BENJAMIN, 2015, p.61).

Segundo Pereira (2009), a análise desses programas possibilita outra perspectiva de olhar para a infância na obra de Benjamin. A autora ressalta que os temas eleitos para a conversa permitem pensar as crianças como interlocutoras.

Benjamin extrai da sua própria experiência o conteúdo das histórias que ele conta. Elas falam da sua infância em Berlim antes da Primeira Guerra e das transformações urbanas trazidas pela sua reconstrução, falam de livros surpreendentes e de escritos instigantes, [...] falam de catástrofes naturais, brinquedos, teatro de marionetes, ciganos, magias, bruxarias, falsificadores de selos e contrabandistas de bebidas, a tomada da Bastilha, exposições universais, etc. As histórias contadas por Benjamin são verdadeiros convites à continuidade - a ler livros que cita, a visitar os lugares que descreve, a buscar saber mais sobre as pessoas a que se refere. (PEREIRA, 2009, p. 269)

2 No texto "A hora das crianças: narrativas radiofônicas de Walter Benjamin", Pereira (2009) explicita que não há nenhum registro sonoro dessa experiência ironicamente vivida num contexto que testemunhava o surgimento de tecnologias de gravação e transmissão de sons. O registro disponível é constituído de escritos que serviram de base para a narração radiofônica alguns redigidos por ele mesmo, outros ditados - e que chegaram até nós graças ao hábito que Benjamin cultivava de arquivar os trabalhos feitos, enviar cópias para amigos/interlocutores ou, ainda, de publicar prévia ou posteriormente os escritos feitos para esse fim.
Nesses programas, encontramos seu posicionamento crítico em relação à infância idealizada, e em diversas narrativas expõe sua crítica aos adultos, como no programa $O$ teatro de marionetes em Berlim, no fragmento: “isto eu digo aqui para alguns adultos que, eu sei, estão aí escondidos em meio às crianças, e pensam que eu não estou vendo" (BENJAMIN, 2015, p. 33). O mesmo pode ser observado em Passeio pelos brinquedos de Berlim I, quando ressalta: "E agora parem de escutar um instante. 0 que vou dizer agora não é para as crianças" (IDEM, p. 65). Essa concepção provoca a refletir como tudo no mundo afeta as crianças. Com notoriedade, conclui ser evidente o fato de as crianças quererem tudo conhecer: "E se os adultos só mostram a elas o lado bem comportado e correto da vida, elas logo vão querer conhecer o outro lado por si mesmas" (BENJAMIN, 2015, p. 99).

Benjamin compartilha com as crianças de sua concepção crítica da história, convocando -as a observarem, chamando atenção para os fatos do cotidiano, resgatando a memória e a experiência pela narrativa como caminho para o sentimento de pertencimento à história. Sua concepção de "escovar a história a contrapelo" aparece quando fala das gentes miúdas, dos esquecidos da história, como no trecho: "vocês não devem pensar que os brinquedos tenham sido desde o começo uma invenção dos fabricantes de brinquedos. Na verdade eles foram surgindo pouco a pouco nas oficinas, pelas mãos dos entalhadores e estanheiro" (BENJAMIN, 2015, p. 71).

Em suas narrativas, Benjamin não apenas convoca as crianças a estarem atentas aos acontecimentos, como parece contar com elas para que estejam comprometidas com o desafio de construir uma experiência compartilhada.

Hoje, para variar, vou simplesmente contar-lhes uma história. Mas antes devo dizer três coisas. Primeiro, tudo nessa história é a mais pura 
verdade. Segundo, é uma história emocionante tanto para adultos quanto para crianças, e as crianças vão entendê-la tão bem quanto os adultos. Terceiro, apesar da personagem principal morrer no final, esta história não tem um verdadeiro fim. Ao contrário, ela tem a vantagem de ser uma história que continua, e assim quem sabe, um dia nós todos saberemos juntos como ela acaba. (BENJAMIN, 2015, p. 171)

Benjamin reconhece nas crianças uma qualidade de escuta e em suas narrativas alerta: se elas não prestarem atenção agora não vai existir o futuro e, assim, o passado ficará esquecido. Com extrema sensibilidade, ele mostra os acontecimentos cotidianos, o popular, o grotesco e o perigo das coisas caírem no esquecimento. O diálogo com Benjamin fornece elementos que questionam nosso olhar em relação às crianças, percebendo-as em sua inteireza e nas singularidades historicamente dadas.

Como adultos, temos na memória nossas lembranças de infância, mas da infância contemporânea só as crianças de hoje podem dizer. E olhando para elas, ouvindo-as, podemos também ouvir nosso tempo. O conhecimento está, então, pautado nas possibilidades de intercambiar experiências por meio de narrativas. Esses são conceitos-chave para pensarmos a reconstrução e a desconstrução das relações contemporâneas entre adultos e crianças. A experiência dialeticamente ligada à narração permite a circulação de saberes da tradição que podem dialogar com saberes que chegam ao mundo pelas novas gerações. A autoridade está na origem da narrativa por meio da experiência. Pela linguagem, as experiências ganham caráter infinito de uma geração para a outra (BENJAMIN, 1994).

Mais do que um relato, a narrativa reflete sobre o processo vivido e explicita o sentido que não é descoberto, mas refeito. Para Benjamin (1994), a narrativa é a forma pela qual se dá o movimento de rememoração, trazendo a possibilidade de troca de experiências, que é sempre partilhada com o outro. Experiência é o que vivemos, sentimos, o que nos faz diferente, o que nos altera, transforma, e que, portanto, carece ser compartilhada, precisa ser contada para os outros. Experiência é abrir mão do perder-se, é fazer existir o que não existia. A experiência é comunicável. As narrativas contam. $\mathrm{E}$, nesse contar, a experiência traz o outro, lhe confere alteridade, diz o que o outro pode nos dar. E o que podemos aprender com as crianças?

A narrativa, ligada à tradição, apoiada na experiência dos adultos e compartilhada com as crianças, é caminho para a construção da história. Entretanto, a narrativa também pode ser contada pelas crianças, que trazem novas formas de olhar. Nesse encontro, reside a possibilidade de fazer o novo no sempre igual.

Olhar para a infância como parte da dinâmica social possibilita a formulação de uma crítica da cultura, assim como, uma crítica da cultura pode possibilitar uma nova experiência de infância. Dessa forma, a aproximação do cotidiano das crianças como experiência de alteridade do lugar do adulto em relação a elas pode nos dar pistas da nossa própria perspectiva a respeito delas, denunciando o que cada época compreende ser a infância e as crianças.

\section{O olhar das crianças: outros olhares para a infância}

Nas entrevistas coletivas realizadas com as crianças, o primeiro apontamento que destacaram a respeito da relação entre elas e os adultos, foi a importância dos adultos em ouvi -las. A relevância da escuta e da credibilidade no que dizem ganhou destaque em suas narrativas:

Eu acho importante ouvir as crianças porque isso é muito sério. Senão fica tudo confundido, falar tudo junto. (Gustavo, 7 anos) 
Quando a gente levanta o dedo, é para os adultos ouvirem. (Rafa, 6 anos)

Às vezes que as crianças estão falando um negócio e os adultos não acreditam. Mas eles têm que ouvir a verdade. (Leo, 9 anos)

Acho bom ouvir as crianças porque elas podem se sentir mais alegres quando são ouvidas. (Rodolfo, 7 anos)

Porque "levantam o dedo"; para não ficar tudo "confundido"; porque os adultos precisam "ouvir a verdade"; ou para que possam "se sentir mais alegres": o pedido das crianças é pela escuta. Que verdade é essa que os adultos não estão conseguindo ouvir? Talvez uma das respostas possa vir da experiência do que é estar no mundo quando se é "pequeno". Quantas vezes as crianças são aquelas sobre as quais falamos e não com quem falamos? Quantas vezes permanecem invisíveis e emudecidas, mesmo quando levantam o dedo?

As crianças expressam nossa responsabilidade enquanto adultos diante das construções inacabadas de uma história que as constituiu no lugar de quem "não fala". Benjamin, ao olhar a história da humanidade e perceber "ecos de vozes que emudeceram", anuncia seu desejo de ruptura: "em cada época é preciso arrancar a tradição ao conformismo, que quer apoderar-se dela" (BENJAMIN, 1994, p. 223224). Para o filósofo, essa é a tarefa da geração atual. O compromisso de tirar as crianças desse lugar é dos sujeitos de agora. Homens, mulheres, crianças, emudecidos, soterrados pelo amontoado de ruínas, vestígio de uma história. Para Benjamin, no presente, é preciso libertarse do futuro para salvar o passado.

Ouvir o que as crianças falam é dar visibilidade a suas manifestações. Por quaisquer que sejam os motivos que impedem esse diálogo, precisamos fazer silêncio para que essa escuta seja garantida. Nesse sentido, a escuta é tomada de consciência, é educar para o diálogo. Enquanto falamos, não ouvimos, e desperdi- çamos a oportunidade de conhecer o que as crianças pensam, como destacado por Raquel, de 9 anos:

É importante saber o que as crianças pensam e por que elas pensam isso. Porque as crianças têm muitas coisas para falar que, na maioria das vezes, os adultos não têm tempo para ouvir, como a imaginação delas, o que elas pensam.

A falta de tempo, no relato da menina, é o que impede os adultos de conhecerem "a imaginação das crianças, as muitas coisas que têm para falar, o que pensam, e por que pensam isso". o que é apontado por Raquel como empecilho para o estabelecimento do diálogo, nas palavras do poeta francês, é marca da vida moderna: "Relógio! Deus sinistro, assustador, indiferente" (BAUDELAIRE, 1985, p. 313). Na ditadura do tempo moderno, o poeta expõe: “Posso garantir que os segundos são agora forte e solenemente acentuados e cada um, jorrando do relógio, diz: 'Eu sou a Vida, a insuportável, a implacável Vida!"” (BAUDELAIRE, 1995, p. 25).

$\mathrm{Na}$ análise dos versos de Baudelaire, feita por Gagnebin, esse é o tempo inimigo que devora a vida, corrompe cada instante da felicidade, cada visão de beleza:

Tempo-vampiro que não remete somente à antiga meditação sobre a vaidade da vida e a futilidade dos prazeres, mas também, segundo Benjamin, à alienação do trabalho capitalista, submetido ao tempo inumano, abstrato e insaciável dos relógios e dos cronômetros. (GAGNEBIN, 2007, p. 52)

Na vida marcada pela falta de tempo, pela dedicação às atividades produtivas e valorização dos resultados, as crianças, "pouco produtivas", deixam de ser interessantes e não resta tempo para ouvi-las.

No diálogo a respeito da relação entre elas e os adultos, uma das crianças entrevistadas destaca a calma como assunto que precisa ser levado em conta: 
Tem um assunto que é sobre a calma. Tem muitos adultos que ainda são um pouco estressados. Então, as crianças ainda são muito novas para aprender que a gente deve respeitar eles $e$ por isso eles devem ter um pouco mais de calma. (Melissa, 8 anos)

Melissa pede calma! É preciso esperar! Ser criança é apontado como condição que espera do adulto mais calma e paciência. No pedido de calma e no que é correlato a esta ideia - espera, paciência, tranquilidade -, há uma contraposição ao tom do nosso tempo. A impaciência dos adultos com as crianças é algo que impacta a experiência da infância.

A amplitude das atividades cotidianas desdobram-se de forma incessante, impondo-nos um ritmo acelerado das experiências de vida. O tempo existe, mas a cada dia os compromissos aumentam e estamos sempre fazendo mais coisas.

A incapacidade do homem ocidental de dominar o tempo (e sua consequente obsessão de 'ganhá -lo' e de 'fazê-lo passar') tem seu primeiro fundamento nesta concepção grega do tempo como um continuum quantificado e infinito de instantes pontuais em fuga. (AGAMBEN, 2005, p. 112)

A busca pelo preenchimento desse tempo parece inacabada, nos impede de desfrutar o sentimento de calma, que na correria diária escorre sem conseguirmos segurar, porque ele exige parada. 0 estado de tranquilidade, de estar calmo, tem a ver com a serenidade, com o relaxamento do corpo inteiro, com o desligar-se das multitarefas. E o que as crianças nos dizem é que sem calma não conseguimos enxergar o outro. Quantas vezes nos relacionamos com crianças e adultos divididos pelo nosso tempo: fisicamente estamos presentes, mas nosso pensamento anda longe, envolvido com outras demandas que nos distanciam de onde estamos.

Nas narrativas, o tema da escuta foi insistentemente trazido pelas crianças. E uma de- las, ao destacar o assunto, justificou sua opinião apresentando a seguinte explicação:

Bianca (8 anos): É importante ouvir as crianças porque elas sabem mais de algumas coisas do que os adultos.

Pesquisadora: Você pode dizer uma dessas coisas?

Bianca: Como lidar com os outros.

A fala de Bianca produziu questionamentos e burburinhos entre as crianças, que começaram a pontuar outras questões que acreditavam poder ensinar aos adultos também. Diferentes falas ressaltaram a possibilidade de contar com suas descobertas, mostrando a importância de ouvi-las a esse respeito. Ao expressarem sua opinião sobre a questão proposta, as crianças deram diferentes destaques para o que consideram como um saber que podem compartilhar com os adultos:

Ensinaria a fazer as coisas que eu aprendo na escola sobre a natureza. Cuidar das árvores, plantas e ser amigo dos bichos. (Gustavo, 7 anos)

A ter mais paz no mundo porque meu pai, ele tem uma loja e ele fica brigando com todo mundo que entra lá e discute com ele. Eu não gosto disso e às vezes eu vejo. Então, eu ensinaria a ter paz no mundo. (Bianca, 9 anos)

As crianças podem ensinar aos adultos a respeitarem o jeito que as crianças são. Se elas são levadas, se elas são bagunceiras, se elas falam muito, gritam muito, tiram nota baixa. (Raquel, 9 anos)

Os adultos podem aprender com as crianças a preservar mais a natureza, cuidar mais das crianças e a saber mais como é ser criança. (Angélica, 8 anos)

Ensinaria a mexer no mato, com plantas, fazer almoço para a gente almoçar, fazer miojo, carne, frango e bacalhau. (Rafa, 6 anos)

Ensinaria um montão de coisa. Cuidar dos bichos com carinho, ficar com carinho na natureza, essas coisas assim. (Luana, 7 anos) 
O que na concepção das crianças os adultos ainda não sabem? O lugar dos outros - e os ensinamentos das crianças - são indispensáveis para nossa realização existencial. E diante dos conhecimentos que compartilhariam com os adultos, um elemento ganha destaque por várias crianças: a necessidade de ensinar aos adultos a se relacionarem com a natureza.

Cabe problematizar o sentimento de pertencimento à natureza como condição humana. Ao contrário do discurso habitual no qual cabe aos adultos a responsabilidade de ensinar às crianças desde muito pequenas a se relacionarem com a natureza, nas entrevistas realizadas, são as crianças que apontam a perda da experiência do adulto, demandando atenção para rupturas que temos experimentado em nossos dias.

Para Benjamin, no declínio da experiência também está a separação entre homem e natureza. Na análise construída por Löwy (1990), "escovar a história a contrapelo", proposição colocada por Benjamin nas "Teses sobre o conceito da história" (BENJAMIN, 1994, p. 225), não se limita à conjuntura precisa que Benjamin vivia no fim dos anos 1930. Para o autor, o duplo protesto de Benjamin - "contra o progresso técnico em armamentos e contra a destruição da natureza - tem um toque profético e uma espantosa atualidade em nossos dias" (LÖWY, 1990, p. 206). Trata-se de uma reflexão fundamental sobre a modernidade, cujo alcance é muito mais vasto e significativo do que um comentário sobre a atualidade política.

Evidentemente, Benjamin não nega que os conhecimentos e as atitudes humanas progrediram (ele o afirma explicitamente nas teses); o que ele recusa obstinada e apaixonadamente, tanto no Passagen - Werk quanto nos outros escritos de seus últimos anos, é o mito - na sua opinião, mortalmente perigoso - de um progresso da própria humanidade que resulta necessariamente das descobertas técnicas, do desenvolvimento das forças produtivas, da dominação crescente sobre a natureza. (LÖWY, 1990, p. 192)

Benjamin havia percebido o distanciamento da natureza com o qual nos deparamos hoje, por meio de sua crítica acentuada ao ímpeto destrutivo e potencialmente bárbaro do progresso capitalista. Previu as consequências da relação de dominação entre homem e natureza, como ressalta em "A caminho do planetário":

Mas, por que a avidez de lucro da classe dominante pensava resgatar nela sua vontade, a técnica traiu a humanidade e transformou o leito de núpcias em um mar de sangue. Dominação da Natureza, assim ensinam os imperialistas, é o sentido de toda técnica. Quem, porém, confiaria em um mestre-escola que declarasse a dominação das crianças pelos adultos como o sentido da educação? Não é a educação, antes de tudo, a indispensável ordenação da relação entre as gerações e, portanto, se se quer falar de dominação, a dominação das relações entre gerações, e não das crianças? E assim também a técnica não é dominação da Natureza: é dominação da relação entre Natureza e humanidade. (BENJAMIN, 1995, p. 69)

Benjamin condena como um ensino imperialista a ideia da dominação da natureza. Conforme explica Löwy, para o filósofo, a exaltação do trabalho e da indústria significa, ao mesmo tempo, o culto ao progresso técnico, "que reduz a natureza a uma matéria-prima da indústria, a uma mercadoria 'gratuita', a um objeto de dominação e de exploração ilimitada" (2005, p. 105).

Como estilhaços das grandes transformações, a relação que estabelecemos com a natureza ganha outros contornos: distanciamento; exploração; destruição; ritmo de vida acelerado; práticas em ambientes fechados; necessidade de aparatos técnicos para nos relacionarmos com a natureza; associação de elementos naturais à sujeira e à doença; compreensão da natureza como sinônimo de peri- 
go; imersão na cultura da limpeza; são posturas que a cada dia nos tornam mais distantes dela.

Em "A doutrina das semelhanças" (1994, p. 108), Benjamin analisa a "faculdade mimética" como responsável pela aprendizagem ocorrente na relação entre homem e natureza, relacionando a sua supressão com a perda da experiência. Para Benjamin, a natureza é determinante na produção de semelhanças, porque aproxima o homem da origem fundamental para o sentido da existência. Nessa perspectiva, o "progresso" significa o fim das diversas formas de manifestação da mimese como possibilidade de identificação entre homem e natureza.

Em nossos dias, a natureza assume um lugar paradoxal: está presente e ao mesmo tempo ausente. É marcada por opostos: proximidade e distância. Fisicamente, o espaço possibilita que tenhamos contato com os diversos elementos naturais. No entanto, a presença da natureza não garante que estejamos em contato com ela. Desatentos ao nosso lugar no espaço, não nos sentimos pertencentes a ele. Tal divórcio traz à tona a acepção mais ampla da natureza como mundo físico, e sua recepção pelos nossos sentidos na relação cotidiana que estabelecemos com ela. Observar, nos sentirmos pertencentes como seres biológicos que somos, apresentam-se como obstáculos a serem superados pelo homem na contemporaneidade.

\section{Crianças e adultos: a possibilidade de um encontro}

No momento de finalização das entrevistas, foi perguntado às crianças se elas gostariam de falar alguma coisa, se tinham alguma pergunta a fazer, e muitas responderam que sim. E, como todo jornal tem sua fala de encerramento, seguimos o roteiro. Entretanto, o fechamento do jornal não foi realizado com uma fala de despedida da jornalista - pesquisadora -, mas das crianças.

Brinquem mais com a gente! (Rodolfo, 7 anos)

Eu gosto do meu avô, da minha avó, e acho que eles devem ser muito bem tratados! (Rafa, 6 anos.

ó! O recado de hoje é que tem que ouvir quando as crianças falarem. Os adultos e os mais velhos ouçam as crianças quando elas falarem as coisas que elas quiserem! (Gustavo, 7 anos)

Mais respeito pelas crianças. Não bata nas crianças. Só brigar, deixar de castigo ao invés de bater de cinto, chinelo, de mão, para não se machucar e também não machucarem o coitado! (Leo, 9 anos)

Vocês não podem bater nas crianças e também não podem botar de castigo. Só quando fizer malcriação! (Gabriel, 6 anos)

Eu queria falar para os adultos pedirem mais ajuda das crianças para fazer as coisas! (Angélica, 8 anos)

Eu acho importante os adultos ouvirem as crianças, porque assim eles podem lembrar da infância e não cometer os mesmos erros com as crianças. Eles vão lembrar que criança também erra e não vão ficar brigando e batendo nas crianças. (Bianca, 8 anos)

ó! Eu queria que os adultos tivessem mais cuidado com as crianças, $e$ as crianças tivessem mais cuidado com os adultos e essas coisas. (Luana, 7 anos)

Mesmo com todo o esforço empreendido na escrita das falas, ouvi-las diretamente do áudio permite considerar a clareza das entonações, o tom que mais parece uma ordem, as risadas e os ruídos. No jornal "ao vivo", aparecem as expressões, o espanto, os "cutucões". 0 exercício do pesquisador é sempre o de compreender e interpretar o que estava sendo significado.

De forma direta ou não - como conselho, pedido ou ordem - na fala de encerramento 
do jornal, temas como a escuta e o cuidado são retomados pelas crianças. Entre as mensagens, há um pedido de cuidado com os avós. É interessante pontuar que de forma recorrente as crianças mencionavam seus avós em suas conversas. Eles apareceram como adultos muito presentes em suas falas, nas mais diversas situações: como quem busca e pega na escola; leva para passear; faz comida; compra coisas; mora na mesma casa. A relação de afeto destacada pelas crianças marca a importância que os avós possuem para elas, e durante o jornal, no pedido para que os avós sejam bem tratados, esse sentimento é reiterado.

Entre os temas destacados, está o desejo de participar: "peçam a ajuda das crianças". A fala traz o tema da participação infantil, atualmente tão discutido nos estudos da infância (O'KANE, 2005; ALDERSON, 2005; JAMES, 2009). A não participação da criança tem muito a ver com o que o adulto pressupõe e julga que ela consegue ou não fazer. Para Delalande,

[...] as crianças não devem ser consideradas apenas em suas relações de dependência dos adultos - seja pela autoridade, seja pelo saber deles -, mas também em sua participação ativa na vida social e cultural, no sentido antropológico. (2009, p. 39)

Além do pedido pela participação, as crianças pedem que não sejam agredidas: "basta brigar e botar de castigo". Já para uma das crianças, isso é permitido "só quando fizer malcriação", o que demonstra em sua fala uma justificativa já assimilada sobre a atitude do adulto.

O erro e a malcriação são motivos apontados para que as crianças apanhem, ou sejam colocadas de castigo. Suas falas nos fazem pensar sobre o que gera o conflito nessa relação. Se ouvíssemos relatos de outras crianças e de adultos a respeito do que compreendem como erro, malcriação, desobediência, razões para a instauração de conflitos, teríamos uma infinidade de respostas que só podem ser dadas a partir das relações estabelecidas cotidianamente entre adultos e crianças. As tensões estão presentes nas relações humanas. $E$ se pensarmos o conflito como divergência de ideias, como um posicionamento diferente do nosso e que por isso se transforma em dificuldade, o desafio posto é a forma como lidamos com ele.

Interessa nesta reflexão problematizar a agressão física destacada pelas crianças como caminho escolhido pelos adultos para a resolução de conflitos. Quando optam pela agressão, adultos se mostram incapazes de se colocarem em uma posição de referência para as crianças que estão sob sua responsabilidade. Elas dizem que o adulto tem que aprender a não bater, e nessa afirmação nos deparamos com o incômodo disso ainda ser a solução para alguns adultos.

As relações estabelecidas com a infância são expressão crítica de uma cultura - brutal, banal - em que não nos reconhecemos. Reencontrar hoje o sentido da solidariedade, restabelecer com as crianças e os jovens laços de caráter afetivo, ético, social e político, exige de nós uma reflexão e uma revisão sobre o papel que temos desempenhado e que estaríamos dispostos e disponiveis a desempenhar neste momento. (BAZÍLIO \& KRAMER, 2006, p. 110)

Discutindo a "solidariedade em tempos de violência", Bazílio \& Kramer (2006) abordam a questão da violência como estratégia que materializa o grau máximo da desigualdade e da exclusão, destacando como ela está "arraigada na nossa tradição e, sobretudo, só será combatida quando o uso da violência contra qualquer cidadão brasileiro se tornar inaceitável" (p.111). Os autores tratam as relações entre adultos, crianças e jovens, no mundo atual, problematizando a perda da autoridade como um dos problemas sociais mais graves do cenário contemporâneo, afirmando que a violên- 
cia se combina com uma autoridade que vai sendo perdida.

Ao investigar a relação de autoridade entre adultos e crianças, Motta (2007) destaca que no processo de sua construção está implicada uma ética entendida como ação, traduzida na ausência de indiferença e na responsabilidade. Assim, a relação assimétrica entre adultos e crianças pode ser tomada como uma relação entre diferentes, mas sem que essa diferença se reverta em opressão.

Torres \& Castro (2014) problematizam como a crise de autoridade hoje se apresenta de forma singular. Por um lado, lamenta-se a "autoridade perdida", pois cria-se uma imagem da ordenação dos lugares da criança e do adulto como se fossem necessários e universais. Por outro, ressente-se da perda daquela autoridade porque não se conseguiu reconstruir as relações com a geração mais nova a partir de outra configuração de direitos e deveres de ambas as partes.

Na perspectiva de Sennet (2001), a autoridade é um compromisso afetivo. Ela só se estabelece quando a atitude de uma pessoa é legitimada pelo outro, ou seja, "é uma expressão emocional de poder" (p. 13). Para o autor, diferentemente da autoridade que implica algo de produtivo, pois se origina da palavra "autor", a palavra "autoritário" descreve uma pessoa ou um sistema repressivo, fazendo a obediência ocorrer por obrigação ou medo. Afirma que as pessoas se recusam a obedecer àqueles que consideram ilegítimos. Para Sennet, falar da autoridade como um processo de interpretação do poder é levantar a questão sobre quanto o sentimento de autoridade existe nos olhos de quem vê.

A partir das contribuições desses autores, entende-se que a autoridade a ser exercida pelos adultos deve ser a favor de colocá-los em um lugar de referência e cuidado reconhecido pelas crianças, em contraposição à agressão.
Para Kramer (2006), hoje vivemos o paradoxo de ter um conhecimento teórico avançado sobre a infância, enquanto assistimos à incapacidade da nossa geração de lidar com as populações infantis. "As crianças - com quem poderíamos aprender a mudar e a fazer história do lixo e reinventar a esperança - aprendem com os adultos a aniquilação dos direitos, o medo, a agressão" (KRAMER, 2006, p. 93).

$O$ adulto bate para educar e é isso que ensina para aqueles que estão sob sua responsabilidade: a mudança de comportamento pela correção ou medo. Na contramão desse ensino, as crianças denunciam a agressão como marca de uma geração que não conseguiu construir relações alteritárias entre gerações diferentes.

Enfatizando o abismo entre as gerações e a "alteridade em ruínas" apontados na relação entre adulto e criança, Pereira \& Jobim e Souza (1998) destacam que se pensarmos "dialeticamente esse arruinamento", encontramos a origem de um diálogo que se apresenta em germe na capacidade da criança em tornar-se tradutora, para o adulto, de uma linguagem que ele próprio construiu.

Nesse diálogo feito em desvio, a possibilidade de um encontro (um tanto desencontrado) das diferentes temporalidades e linguagens que constituem a criança e o adulto, bem como a de construção de um conhecimento pautado eticamente no resgate do princípio da alteridade. (PEREIRA \& JOBIM E SOUZA, 1998, p. 40, grifo das autoras)

Em detrimento da alteridade, o distanciamento tem dado o tom dessa relação, e o que temos presenciado em nossos dias é a propagação da necessidade de um mercado com suas especificidades - cursos, manuais e outros aparatos e produções como revistas, livros, sites, blogs - e de pessoas especializadas em mediar essa relação. O desconhecimento das crianças garante o lugar de personagens 
como a SuperNanny ${ }^{3}$ - humanas ou em aparatos - que sabem de tudo, regulam interações, terceirizando a educação das crianças, criando interdições para uma convivência mais autêntica entre elas e os adultos.

Na contemporaneidade, estão postos os empecilhos que distanciam crianças e adultos: rotina cheia de compromissos; crise de autoridade; deslocamento do lugar ocupado por ambos; dificuldade em estabelecer diálogo; a lógica do próprio tempo; crianças ocupadas; organização da vida e das relações de trabalho; afastamento; individualismo; qualidade da relação comprometida que gera verdadeiros abismos.

Como na fala de uma das crianças, que haja possibilidade "dos adultos terem mais cuidado com as crianças, e as crianças com os adultos". É preciso buscar pistas que apontem o cuidado como ação que envolve responsabilidade, resposta ao outro, respeito, ética.

\section{Considerações finais}

Neste texto, a produção do conhecimento caminhou na direção da escuta das crianças a respeito das relações estabelecidas entre elas e os adultos. Contrapondo-se à ideia de falta, incompletude e inacabamento mostraram com seu jeito de ser e fazer a reivindicação de outro lugar para elas: o de quem deseja ser ouvido.

No encontro com as crianças, torna-se possivel traçar caminhos para a alteridade, e elas nos dão pistas: estar junto, ter tempo, dialogar, olhar de perto, com mais calma, como elas pe-

3 SuperNanny foi um programa de televisão criado na Inglaterra e adaptado a outros países, como Estados Unidos e Brasil. A ideia é mostrar em cada capítulo como impor disciplina a crianças. Nos Estados Unidos, a personagem Nanny é uma babá, interpretada pela britânica Joanne A. Frost, conhecida como JoFrost. A versão brasileira desse programa estreou no Sistema Brasileiro de Televisão (SBT), canal de TV aberta, em 2006, sendo apresentado pela pedagoga argentina Cris Poli, que foi escolhida entre várias candidatas após uma longa seleção. O programa era exibido aos sábados à noite, e teve sua última temporada em 2013. Em 2014, o canal exibiu apenas as reprises do programa. dem. Ouvir o que elas têm a dizer é compreender as crianças como depoentes privilegiados de sua condição.

Ser criança é apontado como condição que espera do adulto escuta, credibilidade, tempo, espera, paciência, calma. Nesse pedido, há uma contraposição ao tom do nosso tempo, marcado pela pressa e pelo trabalho que impactam diretamente a experiência da infância. A velocidade dos acontecimentos não se limita às transformações tecnológicas, alterando modos de produção, da economia, da cultura, mas afeta também relações estabelecidas entre os homens.

As crianças não reproduzem diretamente o mundo dos adultos, mas são capazes de estabelecer uma nova relação com o que o mundo lhes apresenta. Entre o que está instituído e o que instituem com seus significados e ações, falam da impossibilidade de se proteger alguém com base na violência, denunciando um ensinamento por parte dos adultos que elas não reconhecem como legitimo. Em seus discursos, isso é algo que os adultos ainda precisam aprender.

Convidam a pensar de que forma regras e punições estão fazendo efeito para elas, o que está diretamente relacionado com um olhar de responsabilidade e compromisso para com as crianças. Autoridade é fundamental, é uma forma de demonstrar interesse por elas, a serviço tanto do cuidado, quanto da apresentação de um mundo que as precede. Na relação entre adultos e crianças, lidar com o que é diverso apresenta-se como dificuldade, conflito, colocando como desafio a construção de uma autoridade que não as desrespeite.

O lugar que as crianças ocupam nessa investigação não se justifica por uma ingenuidade por parte delas, mas pelo interesse em resgatar a condição de estranhamento inerente ao confronto com o outro como condição tanto do diálogo, quanto da produção do conhecimento. Importa o reconhecimento do 
valor produtivo que essa relação alteritária entre adultos e crianças exerce como possibilidade de olhar criticamente para a história e a cultura de uma época. Nesse sentido, perguntar por nós mesmos, enquanto humanos, é tarefa antropológica por excelência, e as crianças falam que observam ligações intrínsecas à condição humana se rompendo, e entre elas, o sentimento de pertencimento à natureza. A ausência apontada pelas crianças pode ser um caminho de saudade do lugar que nos encontramos hoje. É como se anunciassem que é preciso retomar essa relação, superando o afastamento e o isolamento.

Valorizar particularidades que a infância guarda não significa considerar as crianças autônomas em relação aos adultos. Ouvir o que elas têm a dizer muitas vezes não se configura como uma questão para o adulto, posto que, por ser adulto, sabe das necessidades da infância e, por isso, prescinde da opinião infantil. 0 ponto de vista das crianças a respeito de suas experiências no mundo vem sendo contado a partir da apresentação do adulto, o que significa dizer que a história não tem sido contada por todos, e as crianças não têm tido a oportunidade de narrar essa história por si mesmas. Assim, abrimos mão de uma alternativa de encontro entre as gerações; não nos tornamos ouvintes das histórias narradas pelas crianças e deixamos de saber o que têm a dizer.

Como adultos, temos na memória nossas lembranças de infância, mas da infância contemporânea só as crianças de hoje podem dizer. E olhando para elas, ouvindo-as, podemos também ouvir nosso tempo. Com condições concretas por viver neste mundo - que é do adulto e dela também - a criança, como o outro do diálogo, é reveladora dela mesma e de nós, enquanto adultos no mundo.

\section{Referências}

AGAMBEN, Giorgio. Infância e história: destruição da experiência e origem da história. Tradução de Burigo. Belo Horizonte. Ed. UFMG, 2005.

ALDERSON, Pia. Crianças como investigadoras: os efeitos dos direitos de participação na metodologia de investigação. In: CHRISTENSE, Pia.; JAMES, Allison. Investigação com crianças: perspectivas e práticas. Porto: Escola Superior de Educação de Paula Frassinetti, 2005. p. 261-280.

BAUDELAIRE, Charles. As flores do mal. Tradução de Ivan Junqueira. 4. ed. Rio de Janeiro: Nova Fronteira, 1985.

BAUDELAIRE, Charles. 0 Spleen de Paris: pequenos poemas em prosa. Tradução de Leda Tenório da Motta. Rio de Janeiro: Imago Ed., 1995.

BAZÍLIO, Luiz Cavaliere; KRAMER, Sonia. Infância, educação e direitos humanos. 2. ed. São Paulo: Cortez, 2006.

BENJAMIN, Walter. A hora das crianças: narrativas radiofônicas de Walter Benjamin. Tradução de Aldo Medeiros. Rio de Janeiro: Nau Ed., 2015.

BENJAMIN, Walter. Obras escolhidas. Magia e técnica, arte e política. Ensaios sobre literatura e história da cultura. Tradução de Sérgio Paulo Rouanet. 7. ed. São Paulo: Brasiliense, 1994.

BENJAMIN, Walter. Obras escolhidas II. Rua de mão única. Tradução de Rubens Rodrigues Torres Filho e José Carlos Martins Barbosa. 5. ed. São Paulo: Brasiliense, 1995.

BENJAMIN, Walter. Origem do drama barroco alemão. Tradução de Sérgio Paulo Rouanet. São Paulo: Brasiliense, 1984.

BENJAMIN, Walter. Reflexões sobre a criança, o brinquedo e a educação. Tradução de Marcus Vinícius Mazzari. São Paulo: Duas Cidades; Ed. 34, 2002.

CAMPOS, Maria. Malta. Por que é importante ouvir a criança? A participação das crianças pequenas na pesquisa científica. In: CRUZ, Silvia. Helena. Vieira. (Org.). A criança fala: a escuta de crianças em pesquisas. São Paulo: Cortez, 2008. p. 35-42.

CHRISTENSEN, Pia; JAMES, Allison. Investigações com crianças: perspectivas e práticas. Porto: Escola 
Superior de Educação de Paula Frassinetti, 2005.

DELALANDE, Julie. Aprender entre crianças: o universo social e cultural do recreio. In: LOPES, Jader Janer Moreira; MELLO, Marisol Barenco. "0 jeito de que nós crianças pensamos sobre certas coisas" dialogando com lógicas infantis. Rio de Janeiro: Rovelle, 2009. p. 23-42.

GAGNEBIN, Jeanne Marie. História e narração em Walter Benjamin. 2. ed. São Paulo: Perspectiva, 2007.

JAMES, Allison. Conceitos de infância, criança e agência: a construção de hospitais infantis na Inglaterra como estudo de caso. $\mathbf{0}$ social em questão, Rio de Janeiro, Pontifícia Universidade Católica do Rio de Janeiro, v. 21, n. 21, p. 45-60, dez. 2009.

KRAMER, Sonia. Infância, cultura contemporânea e educação contra a barbárie. In: BAZÍlIO, Luiz Cavaliere; KRAMER, Sonia. Infância, educação e direitos humanos. São Paulo: Cortez, 2006. p. 83-106.

KRAMER, Sonia. Por entre as pedras: arma e sonho na escola. 3. ed. São Paulo: Ática, 1993.

KRAMER, Sonia. Verbete criança. Belo Horizonte, MG: Faculdade de Educação; Gestrado; Fae; UFMG, 2011. (Verbete no dicionário "Trabalho, profissão e condição docente"). Disponivel em: <http://www. gestrado.net.br/?pg=dicionario-verbetes $\& \mathrm{id}=107>$. Acesso em: 5 jan. 2020.

LÖWY, Michael. Romantismo e messianismo: ensaios sobre Lukács e Walter Benjamin. Tradução de Myrian Veras Baptista e Magdalena Pizante Baptista. São Paulo: Perspectiva, 1990.

LÖWY, Michael. Walter Benjamin: aviso de incêndio. Uma leitura das teses "Sobre o conceito de história". Tradução de Wanda Nogueira Caldeira Brant. São Paulo: Boitempo Ed., 2005.

MACEDO, Nélia. Mara. Rezende. et al. Encontrar, compartilhar e transformar: reflexões sobre a pesquisa intervenção com crianças. In: PEREIRA, Rita. Marisa. Ribes.; MACEDO, Nélia. Mara. Rezende. (Org.). Infância em pesquisa. Rio de Janeiro: NAU Ed., 2012. p. 87-108.

MOTTA, Flavia Miller Naethe. As crianças e o exercício das práticas de autoridade. 2007. 131p. Dissertação (Mestrado em Educação) - Programa de PósGraduação em Educação, Pontifícia Universidade Católica do Rio de Janeiro, Rio de Janeiro, 2007.

O'KANE, Claire. O Desenvolvimento de técnicas participativas: facilitando os pontos de vista das crianças acerca de decisões que as afetam. In: CHRISTENSE, Pia.; JAMES, Allison. Investigação com crianças: perspectivas e práticas. Porto: Escola Superior de Educação de Paula Frassinetti, 2005. p. 143-170.

PEREIRA, Rita Marisa Ribes. A hora das crianças: narrativas radiofônicas de Walter Benjamin. In: JOBIM e SOUZA, Solange.; KRAMER, Sonia. (Org.). Política, cidade e educação: itinerários de Walter Benjamin. Rio de Janeiro: Contraponto, 2009. p. 259-278.

PEREIRA, Rita Marisa Ribes; JOBIM e SOUZA, Solange. Infância, conhecimento e contemporaneidade. In: KRAMER, Sonia.; LEITE, Maria Isabel. (Org.). Infância e produção cultural. Campinas, SP: Papirus, 1998. p. 25-42.

SARMENTO, Manuel. Jacinto. Estudos da infância e sociedade contemporânea: desafios conceituais. $\mathbf{0}$ social em questão, Rio de Janeiro, Pontifícia Universidade Católica do Rio de Janeiro, v. 21, n. 21, p. 1544, dez. 2009.

SENNETT, Richard. Autoridade. Tradução de Vera Ribeiro. Rio de Janeiro: Record, 2001.

TORRES, Maria Carmem Eulen; CASTRO, Lucia Rabello. Disponibilidade ao outro: construindo novas formas de autoridade entre adultos e crianças. Psicologia da Educação, São Paulo, n. 38, p. 87-99, 1. sem. 2014. Disponivel em: <http://pepsic.bvsalud. $\mathrm{org} / \mathrm{pdf} / \mathrm{psie} / \mathrm{n38} / \mathrm{n} 38 \mathrm{a} 08$.pdf>. Acesso em: $10 \mathrm{abr}$. 2020.

Recebido em: 28/04/2020 Revisado em: 02/08/2020 Aprovado em: 05/08/2020

Gabriela Barreto da Silva Scramingnon é doutora em Educação pela Pontifícia Universidade Católica do Rio de Janeiro (PUC-Rio). Professora do Departamento de Didática da Universidade Federal do Estado do Rio de Janeiro (Unirio). Membro do grupo de pesquisa Educação Infantil e Políticas Públicas (EIPP). E-mail: gabrielabasil@gmail.com 